Akman, M., Sakarya, S, Sargin, M., Ünlüoğlu, I., Taşkın Eğici, M., Boerma, W.G.W., Schäfer, W.L.A. Changes in primary care provision in Turkey: a comparison of 1993 and 2012. Health Policy: 2016

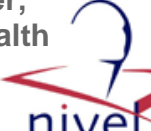

\begin{tabular}{l|l}
$\begin{array}{l}\text { Postprint } \\
\text { Version }\end{array}$ & 1.0 \\
Journal website & http://www.healthpolicyjrnl.com/article/S0168-8510(16)30324-4/fulltext \\
\cline { 2 - 2 } Pubmed link & \\
DOI & $10.1016 /$ j.healthpol.2016.11.016
\end{tabular}

This is a NIVEL certified Post Print, more info at http://www.nivel.eu

\title{
Changes in primary care provision in Turkey: A comparison of 1993 and 2012
}

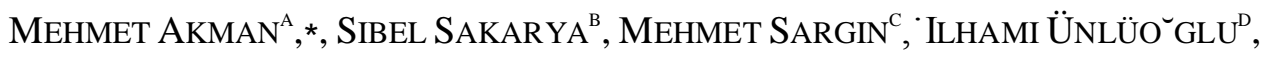 \\ MEMETTAS, KIN E־ GICI ${ }^{\mathrm{E}}$, WIENKE G.W. BOERMA ${ }^{\mathrm{F}}$, WILLEMIJN L.A. SCHÄFER ${ }^{\mathrm{F}}$ \\ aMarmara University School of Medicine, Family Medicine Department, Istanbul, Turkey \\ bMarmara University School of Medicine, Public Health Department, Istanbul, Turkey \\ cMedeniyet University Medical Faculty, Family Medicine Department, Istanbul, Turkey \\ dEskis, ehir Osmangazi University Medical Faculty, Family Medicine Department, Eskisehir, \\ Turkey \\ eS, is, li Hamidiye Etfal Research and Education Hospital, Family Medicine Clinic, Istanbul, \\ Turkey \\ fNIVEL, the Netherlands Institute for Health Services Research, Utrecht, Netherlands
}

\begin{abstract}
Since the early 1990s, the primary care system in Turkey has undergone fundamental changes. In the first decade of the millennium family doctor scheme was introduced to the Turkish primary care sector and the name of the primary care doctors (PCDs) changed from "general practitioner" (GP) to "family doctor" (FD). This study aims to give an insight into those changes and to compare the service profiles of PCDs in 1993 and 2012. Data, based on cross sectional surveys among Turkish doctors working in primary care are derived from the 1993 European GP Task Profile study $(n=199)$ and the 2012 Quality and Costs of Primary Care in Europe (QUALICOPC) study $(\mathrm{n}=299)$. The study focuses on the changes in the primary care service provision based on selected aspects such as the first contact of care, preventive care, and the knowledge exchange and collaboration with other health professionals. Compared to GPs in 1993, FDs in 2012 reported that their involvement in treatment of chronic diseases, first contact care, antenatal and child health care have increased. FDs have more contact with other primary healthcare workers but their contact with hospital consultants have decreased. Overall, the services provided by PCDs seem to be expanded. However, the quality of care given by FDs and its effects on health indicators are needed to be explored by further studies.
\end{abstract}

\section{INTRODUCTION}

The health care reforms that have taken place in Turkey over the last decade, were inspired by the evidence that stronger primary care contributes to better performance of health care systems overall [1], [2], [3] and [4]. Prior to these reforms, primary 
Akman, M., Sakarya, S, Sargin, M., Ünlüoğlu, I., Taşkın Eğici, M., Boerma, W.G.W., Schäfer, W.L.A. Changes in primary care provision in Turkey: a comparison of 1993 and 2012. Health Policy: 2016

health care services in Turkey were organized in accord with the 1961 Law on the Socialization of Health Services. According to this law primary care services were provided by health centers (HCs), staffed by teams consisting of a doctor, a nurse, a midwife, and an environmental health technician and an administrator in larger centers (5). Primary care doctors (PCDs) working in HCs were called as "general practitioners” (GPs). In Turkey the term GP refers to a primary care doctor who is a medical graduate with no formal vocational training in general practice/primary care or any other medical specialty. Salary based payments were the main source of income for these primary care doctors. Turkish GPs working in any given HC were collectively responsible for the service provision to a geographically predefined area with a population of 5000-10,000. All running costs of these centers were provided by Ministry of Health (MoH).

To establish a stronger primary care system, in 2003 the Turkish government introduced the "Health Transformation Program" (HTP). This reform program was implemented between 2003-2010 to close the quality gap between the healthcare system in Turkey, and those in Europe and other Organisation for Economic Cooperation and Development (OECD) countries [6]. Introduction of family doctor (FD) scheme for primary care services; introduction of general health insurance (all existing insurance schemes gathered under one umbrella), and financial and executive independence of public hospitals were the major initiatives of the HTP [7]. The FD scheme first introduced as a pilot program in 2003 and was then extended to cover the whole country at the end of 2010. It was the core tenet of HTP with a view to strengthen the primary care service in the country, by fully replacing the former HCs. Since the number of medical graduates who completed a three-year postgraduate vocational training in family medicine (family medicine specialists) was limited, those primary care doctors who were formerly called "GPs" were redesignated as "FDs" after completing a 10 days orientation course [8]. With the introduction of new structure, the FDs are paid on a capitation basis with incentives for selected preventive services. In general, the income of FDs has increased significantly (more than two folds). The HCs which are now called "Family Health Centers" (FHC) are consisted of a core team of a FD and a nurse or a midwife. After the implementation of the HTP, the responsibility of running the FHC has given to the FD, a major change which was aligned with the major aim of HTP: evolving the function of $\mathrm{MoH}$ from an administrator to a planner and supervisor.

Along with these changes the $\mathrm{MoH}$ started to employ FDs as contracted independent professionals, whereas in old structure they were government employees, no different than any other civil servant with permanent positions. However, the main service areas of FHC remained similar to the former HCs to a great extent with an exception of community based services such as environmental health and school health that are provided by public health units (named as Community Health Centers (CHC) after the reforms). One of the significant changes that the reforms brought was that each FD were initially given pre-assigned patient list (per maximum of 4000 patients per FD) to work with; however, the patients were free to change their FDs if they wished. Facilities for the FHC were improved compared to former HCs including computerization enabling electronic record keeping [5], [6], [7] and [8]. Despite all structural and procedural reforms within primary care, and the increase in health expenditure, a recent study has found that the structure and delivery process of primary care in Turkey was not as strong compared to most countries in Europe 
Akman, M., Sakarya, S, Sargin, M., Ünlüoğlu, I., Taşkın Eğici, M., Boerma, W.G.W., Schäfer, W.L.A. Changes in primary care provision in Turkey: a comparison of 1993 and 2012. Health Policy: 2016

[9] and [10]. The lack of manpower in primary care, both quantitatively and qualitatively (47 FD per 100.000 population in 2013, with less than $10 \%$ of them having completed a postgraduate vocational training), the high number of patients per FD (the average number of patients per FD was 3621 in 2013) and the disproportionately low number of primary care encounters among total outpatient clinical activity per year (less than $40 \%$ ) have been reported as the areas for improvement [11] and [12]. In the absence of a compulsory referral chain from primary care to specialist settings, patients can enter into the healthcare system at whatever point they prefer. This disjointed healthcare provision, along with the increased workload (between 2002 and 2012 annual per capita PCD visits increased approximately by three fold whereas total number of PCDs increased only around $35 \%$ ) of FDs has resulted in significant inefficiencies at the primary care level [8] and [12]. Various studies evaluating the Turkish healthcare during the last decade have been focused mainly on the provider or user views about the new organization of the primary care services [5], [13], [14], [15], [16] and [17]. However, an evaluation that explored the changes within primary care over time has been lacking. This is the first study, which aims to give a detailed insight into the changes that have taken place in the Turkish primary care, and compare the service profiles of PCDs in 1993 and 2012. However, assessment of the HTP implementation process is out of scope of this study. This study rather focuses on the changes in the primary care service provision based on selected aspects such as PCDs being the first contact of care, the involvement of PCDs in various services, and the knowledge exchange and collaboration with other health professionals. This study will aim to explore as to whether the breadth of the service profile of PCDs has expanded.

\section{MATERIALS AND METHODS}

Data, based on the cross sectional questionnaire-based surveys among PCDs have been derived from the 1993 European GP Task Profile study and the 2012 Quality and Costs of Primary Care in Europe (QUALICOPC) study. Both of these studies were multinational, and included 28 European countries.

In 1993, the study sample included a random sample of PCDs in 10 preselected provinces out of all 74 provinces in Turkey. In total, 199 doctors responded (response rate: 50\%). In this sample doctors working in inner city and urban areas were over-represented. In 2012, data was collected from seven provinces of Turkey. Selection of provinces was based on the year the FD scheme was introduced, and the geographical distribution within the country. A quota of $10 \%$ per region was applied for all PCDs with family medicine specialist qualifications working in the region. Final analysis was conducted on data from 299 FDs (response rate: 42.9\%). The details of the sampling procedures of both studies have been described elsewhere [18], [19], [20] and [21]. The questions in the 1993 survey on GP service profiles were repeated in 2012 with the purpose of comparing general practice between the two time points. As the questions and the categories of answers that were used in 1993 were copied either literally or only revised slightly without changing the meaning in 2012, the data is deemed to be comparable [22].

Kringos et al. developed the Primary Health Care Activity Monitor for Europe (PHAMEU) which describes core dimensions of primary care in a multidimensional systematic approach. PHAMEU framework defines three levels: structure, process and outcome. On process level; continuity, access, coordination and 
Akman, M., Sakarya, S, Sargin, M., Ünlüoğlu, I., Taşkın Eğici, M., Boerma, W.G.W., Schäfer, W.L.A. Changes in primary care provision in Turkey: a comparison of 1993 and 2012. Health Policy: 2016

comprehensiveness of care are defined as process dimensions of primary care. For each dimension further precise and measurable indicators are described (in total 9, 12, 7, 10 indicators for continuity, access, coordination and comprehensiveness respectively) [23]. The two cross-sectional surveys that were conducted in 1993 and 2012 contained questions that corresponded with some of the PHAMEU process indicators only; not structure and outcome indicators. Those indicators that are used in this study for comparison purposes are shown in Box 1.

\section{[Box 1]}

For measuring the involvement of PCDs in specific activities related to first contact care, prevention, treatment of chronic diseases and technical procedures; items, such as the first contact for patients with stomach problems, the involvement in the treatment of diabetes and the provision of smoking cessation counselling have been used. On all items for the first contact care, the treatment of diseases and the provision of medical and minor surgical procedures; the respondents were asked to indicate their involvement on a four-point scale ranging from 'never' (one point), to 'almost always or always' (four points). In the analysis of these scales, the first two answer categories (seldom/never and occasionally) and last two (usually and almost always/always) were combined. Contacts with other professionals were also measured with a four-point scale, ranging from 'seldom/never' (one point), to 'more than once a month'. Involvement in the delivery of preventive services (such as measuring blood pressure, checking blood cholesterol level and health education activities) was measured with binary responses of Yes or No. Other comparative questions on four dimensions mentioned above were pre-structured; answers are presented as percentages in the results.

\subsection{Statistical analysis}

Descriptive statistics were run for each study group separately. Chi square test was used for comparative analysis of categorical variables, and t-test or its nonparametric equivalence was used for comparison of continuous variables. $\mathrm{p}<0.05$ was accepted to be statistically significant. Analyses were performed in SPSS version 16.0.

\section{RESULTS}

\subsection{Characteristics of PCDs}

The percentage of female participants of the 1993 (34.2\%) study slightly differs from the sample in 2012 (30.4\%); although not statistically significant $(p>0.05)$. The participants from 1993 were relatively younger than the participants from 2012 ( $30.6 \pm 4.5$ vs $44.0 \pm 6.4 ; \mathrm{p}<0.001$ ). The settings in which the PCDs worked are summarized in Table 1. Compared to 1993, in 2012 a larger percentage of participants were FDs with a vocational training (10\% vs $0.5 \%)$. In both years, doctors working in urban and inner city settings constituted the largest share of participants. Compared to 1993, the 2012 sample included more FDs with a relatively high percentage of elderly patients and there were significantly less FDs with a secretary and a laboratory assistant in their practice. In 2012 the average number of patients per FD was 3642.7 whereas in 1993, there were no patient lists assigned to individual FDs, therefore it is not possible to provide a figure on this (Table 1). 
Akman, M., Sakarya, S, Sargin, M., Ünlüoğlu, I., Taşkın Eğici, M., Boerma, W.G.W., Schäfer, W.L.A. Changes in primary care provision in Turkey: a comparison of 1993 and 2012. Health Policy: 2016

\section{[TABLE 1]}

Compared to 1993, in 2012 PCDs had more face-to-face contact (more than once a month) with other PCDs (52\% vs 72\%; $\mathrm{p}<0.05$ ), nurses (51\% vs $84 \%$; $<<0.05$ ) and pharmacists (19\% vs 36\%; p < 0.05) but less contact (less than once a month) with specialists (30\% vs 16\%; p < 0.05) (Supplement Table S1).

In 1993, 92.1\% of the PCDs had an outpatient clinic where specialist level care was provided less than $10 \mathrm{~km}$ away from their practice; this was $89 \%$ in 2012 . In addition, in 1993 62.5\% had a general or university hospital less than $10 \mathrm{~km}$ away while it increased to $72.2 \%$ in 2012 . The percentage of solo practices increased from four to $12 \%(\mathrm{p}<0.05)$ and the percentage of PCDs sharing practice with specialists decreased from 42.0\% to 8.7\% (p < 0.001) between 1993 and 2012 (Table 1).

\subsection{Comprehensiveness}

In Fig. 1 comparative data regarding first contact care are presented. In general, PCDs involvement in first contact care seem to have increased. For instance, women with psychosocial problems (10.3\% vs 51.5\% in 1993 and 2012 respectively) or a lump in breast (12.9\% vs 58.2\% in 1993 and 2012 respectively) are the two reasons that have seen the biggest increase for a visit to a PCD ( $p<0.001$ for both cases). However, there is a slight decline in the PCDs' involvement as first contact for child abuse (16.6\% vs $10.4 \%$ in 1993 and 2012 respectively) and oral contraceptive requests (38.8\% vs 37.5\% in 1993 and 2012 respectively; $p>0.05$ for both cases). in preventive services. The involvement of PCDs in antenatal care (31.2\% vs $85.6 \%$ in 1993 and 2012 respectively) and blood cholesterol check-ups (47.3\% vs 98.7\% in 1993 and 2012 respectively) has increased most, and blood pressure measurement (45.6\% vs 32.4\% in 1993 and 2012 respectively) and alcohol consumption counselling (86.0\% vs 71.9\% in 1993 and 2012 respectively) have decreased significantly. Fig. 2 also compares the PCDs' involvement in treatment of diseases and performance of medical and minor surgical procedures. In 2012 FDs indicated more involvement in all of the given disease conditions compared to 1993, except for pneumonia. Among the technical procedures a significant decrease is observed in 2012 for wound suturing (67.0\% vs 37.8\% in 1993 and 2012 respectively), setting up an intravenous infusion (60.4\% vs 29.8\% in 1993 and 2012 respectively) and resection of an ingrown toenail (29.7\% vs 22.4\% in 1993 and 2012 respectively) compared to 1993.

\section{[FIGURE 1]}

\section{[FIGURE2 ]}

\section{[Box 2]}

\subsection{Continuity}

There has been a significant increase of the percentage of PCDs who routinely keep medical records (both electronic and physical) of all patients (66\% vs $76 \%$; $\mathrm{p}<0.05)$. In 1993, 76\% of the GPs did not have a computer, whereas in 2012 FDs using computer in their office increased to 93\%. Compared to 1993, in 2012 more FDs declared that they use computer for prescribing ( $8 \%$ vs $70 \% \mathrm{p}<0.001$ ), medical records ( $9 \%$ vs $92 \%$; $<<0.001)$ and research purposes ( $9 \%$ vs $80 \%$; $<<0.001)$. 
Akman, M., Sakarya, S, Sargin, M., Ünlüoğlu, I., Taşkın Eğici, M., Boerma, W.G.W., Schäfer, W.L.A. Changes in primary care provision in Turkey: a comparison of 1993 and 2012. Health Policy: 2016

\subsection{Accessibility}

Regarding the patients seen by appointments there was no significant change between the two studies. In 1993 93.2\% of the PCDs said that they were seeing patients without any appointment beforehand. The percentage was almost identical (93.0\%) in 2012. There was a significant decrease regarding the average number of hours spent on out-of-hours care per week (22.4 h in 1993 vs $3.2 \mathrm{~h}$ in 2012; $\mathrm{p}<0.05)$. In 1993, 50\% of the GPs ( $\mathrm{n}=195)$ stated that they were not involved in the provision of after hour emergency services; $45.6 \%$ stated that they were involved in these services at least on a rotational basis. In 2012 15.1\% of the FDs stated that the patients on their lists can access medical services from their health center after 6 p.m. at least once a week. Of all the FHCs surveyed, 3.7\% were reported to be open at least once a month on weekends.

\section{DISCUSSION}

The results of this first comparative study provide an opportunity to describe the change in the provision of primary care services during the previous two decades in Turkey. Overall, our results demonstrate that the service profile of PCDs appears to have improved according to their own reporting. Major findings could be summarized as follows: FDs' reported higher involvement in chronic diseases, first contact care, antenatal and child health care during the last two decades whereas some aspects of preventive care (blood pressure measurement and alcohol consumption counselling) and technical procedures (wound suturing, intravenous infusion) decreased relatively. In addition, compared to HCs in 1993, FHCs in 2012 have become more computerized. FDs have had more contact with some other health professionals but their contact with hospital consultants has decreased compared to GPs in 1993. FDs had relatively higher number of patients on their assigned lists compared to other European countries in 2012 [24]. Additionally, primary care teams have become smaller independent units, which provide healthcare services to a list of patients rather than a group of health professionals providing service to a population in a given geographical area. Observed differences and reported outcomes by PCDs are categorized as an improvement or decline and presented in Box 2 in relation with appropriate process level dimensions

Observed differences between two cross sectional surveys may be explained by structural changes in primary care in Turkey that took place over the last 20 years. For preventive services, the increased involvement of PCDs in antenatal care and child immunization might be related to the performance system that was introduced through HTP. Payment cuts occur if FDs do not reach the child immunization targets or when they fail to deliver antenatal care to a pregnant woman on their list. Therefore, FDs are highly motivated for achieving a total coverage in these areas. Combined with high number of patients seen per day and with no incentives or reportable outcome measures for some clinical activities such as the blood pressure measurements or alcohol consumption counselling may have been neglected. Furthermore, it is plausible that the incentives for specific performance criteria may have led to over-reporting of certain activities. Recent data suggests the acceptability of this incentive system by healthcare professionals is questionable. In a qualitative study of Turkish FDs described the negative incentives in the performance scheme as a 'degrading method of punishment' [15]. 
Akman, M., Sakarya, S, Sargin, M., Ünlüoğlu, I., Taşkın Eğici, M., Boerma, W.G.W., Schäfer, W.L.A. Changes in primary care provision in Turkey: a comparison of 1993 and 2012. Health Policy: 2016

Another important structural change introduced by FD scheme is definition of a "family health unit" which consisted of one FD and one nurse/midwife. These units are the smallest independent health teams in FHCs, and lack in variety as they do not include other allied health workers compared to the former HCs [13], [15] and [25]. This change creates a suitable environment for an improved communication within primary care health workers, but may not necessarily be conducive to better communication with other health care professionals who are not working in the primary care as demonstrated in our results.

The observed decline in technical procedures in our findings might be related to the risk perception of FDs. Having an individual patient list, assigned to a particular FD may have increased the perception of risks associated with more invasive medical and minor surgical procedures. As well, the introduction of malpractice insurance and the establishment of a patient complaint reporting system (SABIM) may have contributed to decline in the percentages of some of these invasive procedures [26]. In 2012, FDs are significantly older than the GPs in 1993. FDs' perception of their new professional status after structural changes and primary care becoming more of a career option in Turkey compared to the situation two decades ago might be possible explanations for the age difference. In 1993 primary care was perceived more as a temporary work place, a waiting room for doctors until they get a chance for specialization.

Besides the structural changes, the epidemiological and demographic transitions occurred during the previous decades could be the other contributing factors to the significant difference observed in our findings between 1993 and 2012 data predominantly for the reported increase in service episodes in the treatment of chronic diseases and first contact care. As in many other countries, the health agenda in Turkey has been shifting from communicable and vaccine preventable diseases to non-communicable diseases (NCDs) and their relevant complications [25]. In a recent study it has been shown that although at the level of 'content' health policy documents highlighted to the Turkish health care system the importance of the growing burden of NCDs, main challenge for Turkey lies in shortcomings in the ways that such policies are implemented [27]. The proportion of elderly population in Turkey (people over 65 years and older) increased from $5.6 \%$ to $7.9 \%$ between 1993 and 2013 [28]. It has been reported that after the reforms a more inclusive approach to the care of elderly patients in primary care has been in progress [16]. The 2013 the National Burden of Disease Study in Turkey showed that the burden of NCDs rate raised from $71 \%$ of the total disability-adjusted life years (DALYs) in 2002 to $79 \%$ in 2012 [29]. According to the Turkish diabetes epidemiology (TURDEP) study, diabetes mellitus type two prevalence doubled in approximately 10 years reaching $13.7 \%$ in 2010 [30]. As well, the reported increase in cholesterol measurement by FDs in our findings is consistent with the aforementioned epidemiological transition as well as the increased awareness of the relation between high cholesterol and cardiovascular diseases. However, our results do not clearly distinguish to what extend these changes in the indicators (treatment of chronic disease and first contact of care) could be attributed to epidemiological and/or demographic transition or real profile change of PCDs.

\subsection{Challenges for Turkish primary care and areas for improvement}

The reorganization of Turkish primary care was completed at the end of 2010, and since then the health care system is in the process of improving its quality, and 
Akman, M., Sakarya, S, Sargin, M., Ünlüoğlu, I., Taşkın Eğici, M., Boerma, W.G.W., Schäfer, W.L.A. Changes in primary care provision in Turkey: a comparison of 1993 and 2012. Health Policy: 2016

efficiency of care together with capacity building within the health workforce (6\% of the FDs have completed their vocational training in 2013) and increasing the acceptability of the new model by the population [12] and [31]. Results of this study also point out some obstacles and shortcomings of Turkish primary care in its current state. The decline in the amount of contact between FDs and specialists is a matter of concern, despite our finding indicating an increase in the number of general or university hospitals within close proximity of FHCs (62.5\% in 1993-vs $72.2 \%$ in 2012). It has been reported that there is lack of incentives for the tiers of care (primary-secondary and tertiary) to work together and the pay for performance system in the hospitals is essentially creating competition between the two levels of care [13], [14] and [31]. On the other hand, "micro" family health units (doctor-nurse and secretary) assigned to a list of patients in a competitive environment might make the collaboration between FDs difficult, as the FDs might refrain from seeking second opinions from more experienced colleagues for the fear of losing their patients to a more experienced team.

Moreover, the high number of patients per FD (mean 3642.7 patients per doctor according to 2012 data) may have made it more difficult to spare time for some more time-consuming clinical work such as technical procedures and counselling during the regular patient consultations. Diminished home visits might be another consequence of high workload of FDs, prohibiting patients who need home care from accessing primary care services [13] and [15].

According to our results, there is an increase overtime regarding first contact care; however, overall data show that in 6 out of 19 conditions FPs are utilised less than $60 \%$ as the first contact care. This indicates patients bypass GPs/FPs and the gate keeping function of primary care is lacking. Likewise according to the Turkish $\mathrm{MoH}$ Annual Health Statistics, the share of primary care in total outpatient clinical visits per year was 38\% in 2003 which then decreased to 35\% in 2013 [12]. In addition, In Turkey between 2000-2010 there was $8.9 \%$ increase in the number of state hospitals while $80.4 \%$ increase for the private hospitals [32]. These figures highlight the fact that hospital care is still quite dominant, in part because primary care providers do not act as gatekeepers to other providers. Patients can therefore seek care in both family practices and hospitals [31]. The treatment of chronic diseases is an area to be explored further. Findings of recent studies indicated that people with chronic diseases use primary healthcare services mostly to renew prescriptions, which highlights and feeds into the public perception of the role of primary healthcare services [24] and [33].

The 2008 WHO report on the evaluation of the organizational model of Turkey recommended some policy actions including the following [34]:

1.

Improve the coordinating role of FDs by removing obstacles to collaboration and working relations between FDs and medical specialists from the secondary level (strengthening of the gatekeeping role of FDs), as well as further support cooperation and teamwork within primary care

2.

Continue to introduce incentives for good performance, focusing in particular on Improving the quality of services.

The findings of our study are well-aligned with these suggestions, and provide an evidence base for the necessity to act on them. 
Akman, M., Sakarya, S, Sargin, M., Ünlüoğlu, I., Taşkın Eğici, M., Boerma, W.G.W., Schäfer, W.L.A. Changes in primary care provision in Turkey: a comparison of 1993 and 2012. Health Policy: 2016

A strong point of our study is that the data presented in this work is on a sample of doctors for two waves. This has provided us with comparative information on the service delivery of Turkish PCDs before and after the structural reforms took place in primary care. However, there are some limitations in this study. A major one is that, the urban areas of Turkey were overrepresented in both in 1993 and 2012. This limits the ability to generalize the results to rural, and regional areas (in $90 \mathrm{~s}$ the rural population accounted for $41 \%$ of whole country population and the same ratio was $23 \%$ in 2012). Due to large distances to rural centers and lower transportation facilities, one might expect PCD service profiles to be broader in rural areas, which could possibly mean that we would have found more comprehensive service profiles, had more rural areas in both samples been included. Another limitation is that the study compares only two points in time; indicated a cross sectional design. No data is available on the period in between and therefore it is not possible to describe the trends within these two decades. Besides the survey in this study included only process level; structure and outcome levels would be worth studying.

\subsection{CONCLUSION}

Overall, structural changes of primary care in Turkey highlighted the value of primary care. It is expected that primary care can help health systems become more responsive to changing health needs; offer more integrated health delivery; and increase the efficacy of the system overall. Decision makers are searching for models to redesign primary care systems in line with these promises [35]. As an uppermiddle income economy that implemented major primary health care reforms in the first decade of the millennium, Turkey is an example for similar countries planning or undergoing primary care reforms. In service provision it appears that lack of integration between primary and secondary care is problematic. An emphasis on integrated care throughout the health reform process in countries such Turkey is more likely to produce better health outcomes.

Structural change in its current form seems to have a positive effect on the role of PCDs for meeting the population needs in terms of epidemiological and demographical transition in Turkey and the services provided by PCDs seem to be expanded. Although PCDs involvement in treatment of chronic diseases, first contact care and antenatal and child health care have increased in 2012 compared to 1993, the negative performance criteria as applied in Turkish primary care may have created discrepancies in favour of tasks targeted by these criteria and in some cases this might have adverse effects on tasks without incentives. This should be taken into account while introducing performance based bonuses for clinical work in other countries.

The quality of care given by PCDs and its effects on health indicators which was out of scope for this paper need to be explored by further studies. As long as the future improvement areas are concerned, there seems to be a room for improvement in terms of integration of health services and the number of PCDs with postgraduate vocational training. Furthermore, current changes do not seem to increase share of primary care in healthcare provision relative to secondary/tertiary care.

\section{Conflict of interest}

Authors declare no conflict of interest related to this paper and funding of this research has been clarified in the section below. 
Akman, M., Sakarya, S, Sargin, M., Ünlüoğlu, I., Taşkın Eğici, M., Boerma, W.G.W., Schäfer, W.L.A. Changes in primary care provision in Turkey: a comparison of 1993 and 2012. Health Policy: 2016

\section{Funding}

The QUALICOPC (Quality and Costs of Primary Care in Europe) study has been cofunded by the European Commission under the Seventh Framework Programme (FP7/2007-2013; grant agreement 242141). The 1993 GP Task Profile Study was funded from the EC BIOMED 1 programme (contract no. BMH1-CT92-1636).

\section{Acknowledgements}

The authors thank their partners in the QUALICOPC project for their role throughout the study and their coordination of the data collection. Moreover, the authors would like to thank N. Çakmak for his role in the data collection in 1993, to Peter Whetton for editing the English language of the manuscript and to Abdullah Demirkol for his final critical reading.

\section{Appendix A. Supplementary data}

Supplementary data associated with this arti-cle can be found, in the online version, athttp://dx.doi.org/10.1016/j.healthpol.2016.11.016.

\section{REFERENCES}

[1]

P.P. Groenewegen, P. Dourgnon, S. Greß, A. Jurgutis, S. Willems

Strengthening weak primary care systems: steps towards stronger primary care in selected western and eastern European countries

Health Policy, 113 (2013), pp. 170-179

[2]

D.S. Kringos, W.G. Boerma, J. van der Zee, P.P. Groenewegen

Europe's strong primary care systems are linked to better population health but also to higher health spending

Health Affairs, 32 (2013), pp. 4686-4694

[3]

J. Macinko, B. Starfield, L. Shi

The contribution of primary care systems to health outcomes within Organization for Economic Cooperation and Development (OECD) countries, 1970-1998

Health Services Research, 38 (3) (2003), pp. 831-865

[4]

B. Starfield

Primary care: an increasingly important contributor to effectiveness, equity, and efficiency of health services. SESPAS report 2012

Gaceta Sanitaria, 26 (S) (2012), pp. 20-26

[5]

R. Atun, S. Aydın, S. Chakraborty, S. Sümer, M. Aran, I. Gürol, et al.

Universal health coverage in Turkey: enhancement of equity

Lancet, 382 (9886) (2013), pp. 65-99

[6]

R. Akdağ

Turkey Health Transformation Program. Evaluation Report 2003-2010

Turkish ministry of health publications, Ankara (2011) Publication No: 839

[7]

M. Tatar, P. Kanavos

Health care reform in Turkey: a dynamic path in the wake of political consensus

Eurohealth, 12 (1) (2006), pp. 20-22

[8]

M. Tatar, S. Mollahaliloglu, B. Sahin, A. Aydın, A. Maresso, C. Hernández-Quevedo

Turkey Health system review

Health Systems in Transition, 13 (6) (2011), pp. 1-186 
Akman, M., Sakarya, S, Sargin, M., Ünlüoğlu, I., Taşkın Eğici, M., Boerma, W.G.W., Schäfer, W.L.A. Changes in primary care provision in Turkey: a comparison of 1993 and 2012. Health Policy: 2016

[9]

D.S. Kringos

The importance of measuring and improving the strength of primary care in Europe: results of an international comparative study

Turkish Journal of Family Practice, 17 (4) (2013), pp. 165-179

[10]

D.S. Kringos, W.G. Boerma, J. van der Zee, P.P. Groenewegen

Political, cultural and economic foundations of primary care in Europe

Social Science \& Medicine, 99 (2013), pp. 9-17

[11]

M. Akman

Strength of primary care in Turkey

Turkish Journal of Family Practice, 18 (2) (2014), pp. 70-78

[12]

Turkish Ministry of Health

Health statistics yearbook Turkey 2013

Turkish ministry of health publications, Ankara (2014) Publication No: 957; Avaliable at: http://sbu.saglik.gov.tr/Ekutuphane/kitaplar/sa\%C4\%9FI\%C4\%B1k\%20istatistik\%20y\%C4 \%B1II\%C4\%B1\%C4\%9F\%C4\%B1\%202013.pdf (Accessed 04.05.15)

[13]

Z.A. Öcek, M. Çiçeklioğlu, Ü. Yücel, R. Özdemir

Family medicine model in Turkey: a qualitative assessment from the perspectives of primary care workers

BMC Family Practice, 15 (2014), p. 38

[14]

D.S. Kringos, W.G. Boerma, E. Spaan, M. Pellny

A snapshot of the organization and provision of primary care in Turkey

BMC Health Services Research, 11 (2011), p. 90

[15]

M. Çiçeklioğlu, Z.A. Öcek, M. Turk, Ş. Taner

The influence of a market-oriented primary care reform on family physicians' working conditions: a qualitative study in Turkey

European Journal of General Practice, 21 (2) (2015), pp. 97-102

[16]

T. Lağarlı, E. Eser, M. Akdeniz, B. Aydoğdu, Ü. Baklaya, C. Fıra, et al.

Assessing the structural and functional properties of family physician services by using the PCAS (Primary Care Assessment Survey: Primary Care Evaluation Scale)

Turkish Journal of Public Health Scale, 9 (1) (2011), pp. 16-32

[17]

Patient Satisfaction With Prımary Health Care Services

R. Akdag (Ed.)Turkish ministry of health publications, Ankara (2010) Publication No: 806

[18]

W.G. Boerma, J. Van der Zee, D.M. Fleming

Service profiles of general practitioners in Europe. European GP Task Profile Study

British Journal of General Practice, 47 (421) (1997), pp. 481-486

[19]

W.L.A. Schäfer, W.G. Boerma, D.S. Kringos, J.D.M. Gress, S. Heinemann, et al.

QUALICOPC, a multi-country study evaluating quality, costs and equity in primary care BMC Family Practice, 12 (2011), p. 115

[20]

W.L.A. Schäfer, W.G.W. Boerma, D.S. Kringos, E. De Ryck, S. Greß, S. Heinemann, et al.

Measures of quality, costs and equity in primary health care: instruments developed to

analyse and compare primary health care in 35 countries

Quality in Primary Care, 21 (2) (2013), pp. 67-79

[21]

M. Akman, S. Kalaça, M. Sargın, B. Tuncel, I. Unluoglu, M. Ugurlu, W.L.A. Schafer, W.G.W.

Boerma, P.P. Groenewegen

QUALICOPC: a multi-country study evaluating quality, costs and equity in primary care 
Akman, M., Sakarya, S, Sargin, M., Ünlüoğlu, I., Taşkın Eğici, M., Boerma, W.G.W., Schäfer, W.L.A. Changes in primary care provision in Turkey: a comparison of 1993 and 2012. Health Policy: 2016

Turkish Journal of Family Practice, 16 (2) (2012), pp. 68-71

[22]

W.L.A. Schäfer, W.G.W. Boerma, P. Spreeuwenberg, F.G. Schellevis, P.P. Groenewegen

Two decades of change in European general practice service profiles: conditions associated with the developments in 28 countries between 1993 and 2012

Scandinavian Journal of Primary Health Care, 34 (1) (2016), pp. 97-110

[23]

D.S. Kringos, W.G. Boerma, Y. Bourgueil, T. Cartier, T. Hasvold, A. Hutchinson, et al.

The European primary care monitor: structure, process and outcome indicators

BMC Family Practice, 11 (2010), p. 81

[24]

A.A. Wilson Windak, M. Oleszczyk, S. Wilm, T. Hasvold, D. Kringos

The delivery of primary care services

D. Kringos, W.G.W. Boerma, A. Hutchinson, R.B. Saltman (Eds.), Building Primary Care in a changing Europe, European Observatory on Health Systems and Policies, UK (2015), pp. 67-101

[25]

Policies for Tackling Non-communicable Diseases and Risk Factors in Turkey

E. Erkoç, N. Yardım (Eds.)Turkish Ministry of Health Publications, Ankara (2011) Publication No: 809

[26]

Z. Öcek, M. Çiçeklioğlu, U. Yücel, R. Özdemir, M. Türk, Ş. Taner

How did the Family Medicine Model Transform the Primary Care Environment (Aile Hekimliği Birinci Basamak Sağlık Ortamını Nasıl Dönüştürdü?)

Turkish Medical Association Publication, Ankara (2013) Available at: [27]

B. Kilic, S. Kalaca, B. Unal, P. Phillimore, S. Zaman

Health policy analysis for prevention and control of cardiovascular diseases and diabetes mellitus in Turkey

International Journal of Public Health, 60 (s1) (2015), pp. S47-53

[28]

Turkey Demographic and Health Survey

Hacettepe University Institute of Population Studies, Ankara (2014), p. 2013 Avaliable at: http://www.hips.hacettepe.edu.tr/TDHS_2013_main.report.pdf (Accessed 04.04.15) [29]

Turkey Country Assessment. Better Non-communicable Disease Outcomes: Challenges and Opportunities for Health Systems, No. 2

M. Jakab, L. Hawkins, B. Loring, J. Tello, T. Ergüder, M. Kontas (Eds.)WHO Europe, [30] Kopenhagen (2014)

I. Satman, B. Omer, Y. Tutuncu, S. Kalaca, S. Gedik, N. Dinccag, et al.

Twelve-year trends in the prevalence and risk factors of diabetes and prediabetes in Turkish adults

European Journal of Epidemiology, 28 (2) (2013), pp. 169-180

[31]

A. Johansen, A.L. Guisset

Successful Health System Reforms: The Case of Turkey

WHO Europe, Kopenhagen (2012) Avaliable at:

http://disab.saglik.gov.tr/yonetim/Uploads/files/kitaplar/Successful\%20Health\%20System\% 20Reforms-The\%20Case\%20of\%20Turkey.pdf (Accessed 04.04.15)

[32]

The Ministry of Health of Turkey

Health Statistics Yearbook

Refik Saydam Hygiene Center Presidency School of Public Health (in Turkish) (2010)

Available from http://sbu.saglik.gov.tr/Ekutuphane/kitaplar/saglikistatistikleriyilligi2010.pdf

(Accessed 03.04.15) [33] 
Akman, M., Sakarya, S, Sargin, M., Ünlüoğlu, I., Taşkın Eğici, M., Boerma, W.G.W., Schäfer, W.L.A. Changes in primary care provision in Turkey: a comparison of 1993 and 2012. Health Policy: 2016

F. Tanır

The condition of family medicine practices in the Doğankent health, training and research region

Turkish Journal of Public Health, 12 (2) (2014), pp. 91-99

[34]

W.G.W. Boerma, D. Kringos, E. Spaan, M. Pellny, K. Karakaya

Evaluation of the Organizational Model of Primary Care in Turkey

WHO Europe (2008) Avaliable at:

http://www.euro.who.int/_data/assets/pdf_file/0007/53863/E92219.pdf (Accessed

04.04.15)

[35]

Building Primary Care in a Changing Europe

D.S. ringos, W.G.W. Boerma, A. Hutchinson, R.B. Saltman (Eds.)WHO, United Kingdom (2015)

TABLES AND FIGURES

\begin{tabular}{|l|l|}
\hline $\begin{array}{l}\text { Box 1: Indicators used for each dimension of process level to compare } 1993 \text { and } 2012 \text { data according to } \\
\text { PHAMEU framework. }\end{array}$ \\
\hline Dimension & Indicator(s) \\
\hline Coordination & Specialist outreach, cooperation within primary care, shared practice \\
Comprehensiveness & First contact care, treatment and follow-up of diseases, medical technical procedures and preventive care \\
Continuity & Medical record keeping, specialist-PCD communication \\
Access & Opening hours, after hours' primary care, organizational access arrangements, home visits \\
\hline${ }^{*}$ Indicators shown in this box are the only ones included in both surveys. \\
\hline
\end{tabular}


Akman, M., Sakarya, S, Sargin, M., Ünlüoğlu, I., Taşkın Eğici, M., Boerma, W.G.W., Schäfer, W.L.A. Changes in primary care provision in Turkey: a comparison of 1993 and 2012. Health Policy: 2016

Table 1

Background characteristics of PCDs and their practices in 1993 and 2012.

\begin{tabular}{|c|c|c|c|}
\hline & $1993(n=199)$ & $2012(n=299)$ & $\mathrm{p}$ \\
\hline Female $\mathrm{n},(\%)$ & $68,(34.2)$ & $91,(30.4)$ & $>0.05$ \\
\hline Age (years, mean $\pm \mathrm{SD}$ ) & $30.57 \pm 4.50$ & $43.99 \pm 6.43$ & $<0.001^{\mathrm{d}}$ \\
\hline Completed vocational training (n, \%) & $1,(0.5)$ & $30,(10.0)$ & $N A^{e}$ \\
\hline $\begin{array}{l}\text { Location of practice } \mathrm{n},(\%) \\
\text { - Inner city/suburb } \\
\text { - Small town } \\
\text { - Mixed urban-rural/rural }\end{array}$ & $\begin{array}{l}160,(80.4) \\
18,(9.0) \\
21,(10.6)\end{array}$ & $\begin{array}{l}252,(84.3) \\
15,(5.0) \\
32,(10.7)\end{array}$ & $>0.05$ \\
\hline Number of patients per practice (mean \pm SD) & $64718.3 \pm 69191.9^{c}$ & $3642.7 \pm 504.6^{\mathrm{b}}$ & $N A^{e}$ \\
\hline $\begin{array}{l}\text { Number of patients } \\
\text { - Face-to-face at office/day (mean } \pm \text { SD) } \\
\text { - Home visit/week (mean } \pm \text { SD) } \\
\text { - By telephone/day (mean } \pm \text { SD) }\end{array}$ & $\begin{array}{l}34.14 \pm 21.47 \\
6.08 \pm 11.48 \\
4.86 \pm 5.41\end{array}$ & $\begin{array}{l}61.79 \pm 16.48 \\
3.82 \pm 6.52 \\
5.95 \pm 6.65\end{array}$ & $\begin{array}{l}<0.001 \\
<0.05 \\
<0.05\end{array}$ \\
\hline $\begin{array}{l}\text { Practice population same ratio as country population in terms of } \\
\text { - Elderly }(>70) \mathrm{n},(\%) \\
\text { - Socially disadvantaged groups } \mathrm{n},(\%) \\
\text { - Ethnic minorities } \mathrm{n},(\%)\end{array}$ & $\begin{array}{l}75,(44.9) \\
49,(27.7) \\
14,(12.1)\end{array}$ & $\begin{array}{l}182,(60.9) \\
105,(35.1) \\
46,(15.4)\end{array}$ & $\begin{array}{l}<0.001^{\mathrm{f}} \\
>0.05 \\
>0.05\end{array}$ \\
\hline $\begin{array}{l}\text { Additional work other than working as PCD n, (\%) } \\
\text { Working status }{ }^{\mathrm{a}} \mathrm{n},(\%)\end{array}$ & $24,(12.1)$ & $1,(99.3)$ & $N A^{e}$ \\
\hline $\begin{array}{l}\text { Salaried } \\
\text { Self-employed with contracts with authority }\end{array}$ & $\begin{array}{l}185(96.9) \\
-\end{array}$ & $\begin{array}{l}273(92.9) \\
19(6.5)\end{array}$ & $>0.05$ \\
\hline $\begin{array}{l}\text { Sharing practice } \mathrm{n},(\%) \\
\text { Solo } \\
\text { With other GPs } \\
\text { With specialists }\end{array}$ & $\begin{array}{l}8(4.0) \\
177(93.5) \\
83(42.0)\end{array}$ & $\begin{array}{l}36(12.0) \\
263(88.0) \\
26(8.7)\end{array}$ & $\begin{array}{l}\mathrm{p}=0.002^{\mathrm{f}} \\
\mathrm{p}>0.05 \\
\mathrm{p}<0.001^{\mathrm{f}}\end{array}$ \\
\hline $\begin{array}{l}\text { Personnel working in the same } \operatorname{center}^{\mathrm{a}} \mathrm{n},(\%) \\
\text { Practice nurse } \\
\text { Secretary } \\
\text { Laboratory assistant }\end{array}$ & $\begin{array}{l}188(95.9) \\
148(75.5) \\
131(66.8)\end{array}$ & $\begin{array}{l}292(97.7) \\
112(37.5) \\
57(19.1)\end{array}$ & $\begin{array}{l}\mathrm{p}>0.05 \\
\mathrm{p}<0.001^{\mathrm{f}} \\
\mathrm{p}<0.001^{\mathrm{f}}\end{array}$ \\
\hline
\end{tabular}

a Categories are not mutually exclusive.

b Practice sizes declared as $>4000$ were calculated as 4000 due to regulations not allowing FDs having more than 4000 pts on their list.

c In 1993 there was no patient list per GP. Therefore these numbers are more likely to be patients per health center (group of GPs).

d Student $t$-test.

e NA: not applicable.

${ }^{\mathrm{f}}$ Chi square test. 
Akman, M., Sakarya, S, Sargin, M., Ünlüoğlu, I., Taşkın Eğici, M., Boerma, W.G.W., Schäfer, W.L.A. Changes in primary care provision in Turkey: a comparison of 1993 and 2012. Health Policy: 2016

Child aged 8 with hearing problem*

Child with severe cough*

Man aged 52 with alcohol addiction problems*

Man aged 32 with sexual problems*

Woman aged 50 with psycho-social problems*

Couple with relationship problems*

Anxious man aged 45

Man aged 28 with a first convulsion

Man aged 35 with sprained ankle*

Woman aged 75 with moderate memory problems*

Man aged 70 with joint pain*

Woman aged 60 with acute symptoms of paralysis/paresis*

Woman aged 60 with polyuria*

Woman aged 60 with deteriorating vision*

50 years old woman with a lump in breast*

24 years old man with stomach pain

45 years old man with chest pain*

13 years old abused child

18 years old woman requesting oral contraception

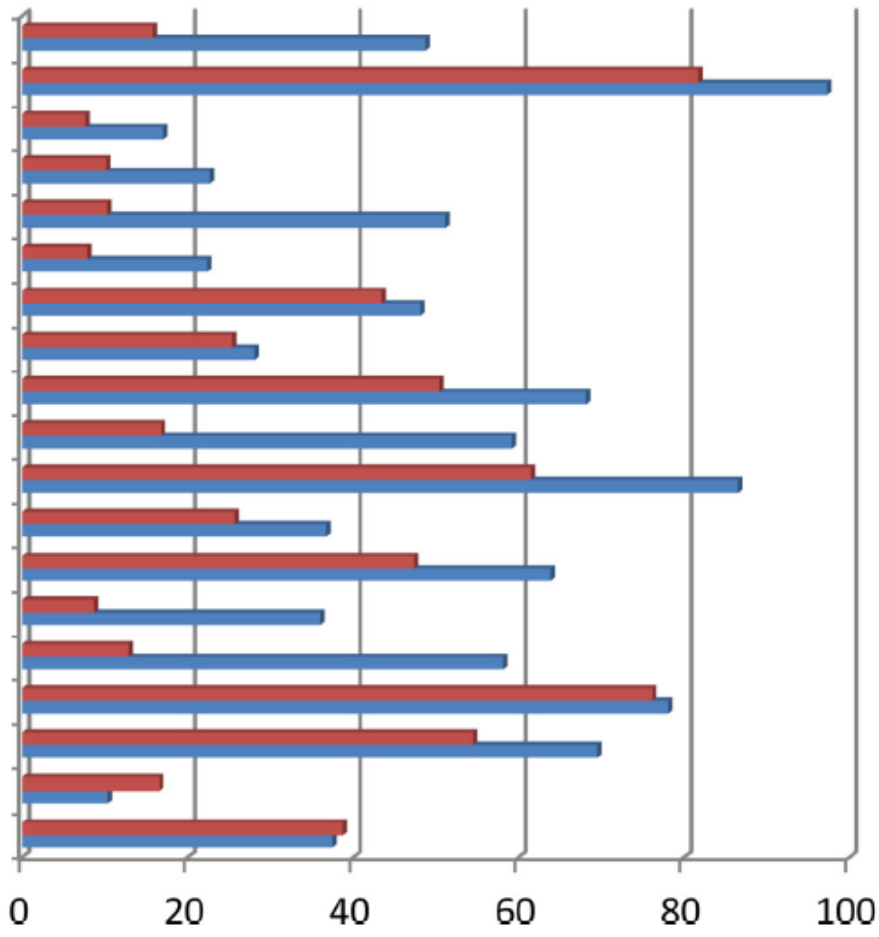

Fig. 1. First contact care status of PCDs for the selected conditions in 1993 and 2012(\%)

aPercentages reflect the PCDs who are usually or almost always first contact of care for the given patients $\left({ }^{*} p<0.001\right)$.

Original question proposed to participants: In case of the following health problems, to what extent will patients in your practice population (people who normally apply to you for primary medical care) contact you as the first health care provider? (This is only about the first contact, not about further diagnosis or treatment). 
Akman, M., Sakarya, S, Sargin, M., Ünlüoğlu, I., Taşkın Eğici, M., Boerma, W.G.W., Schäfer, W.L.A. Changes in primary care provision in Turkey: a comparison of 1993 and 2012. Health Policy: 2016

a) Preventive care services (\%)

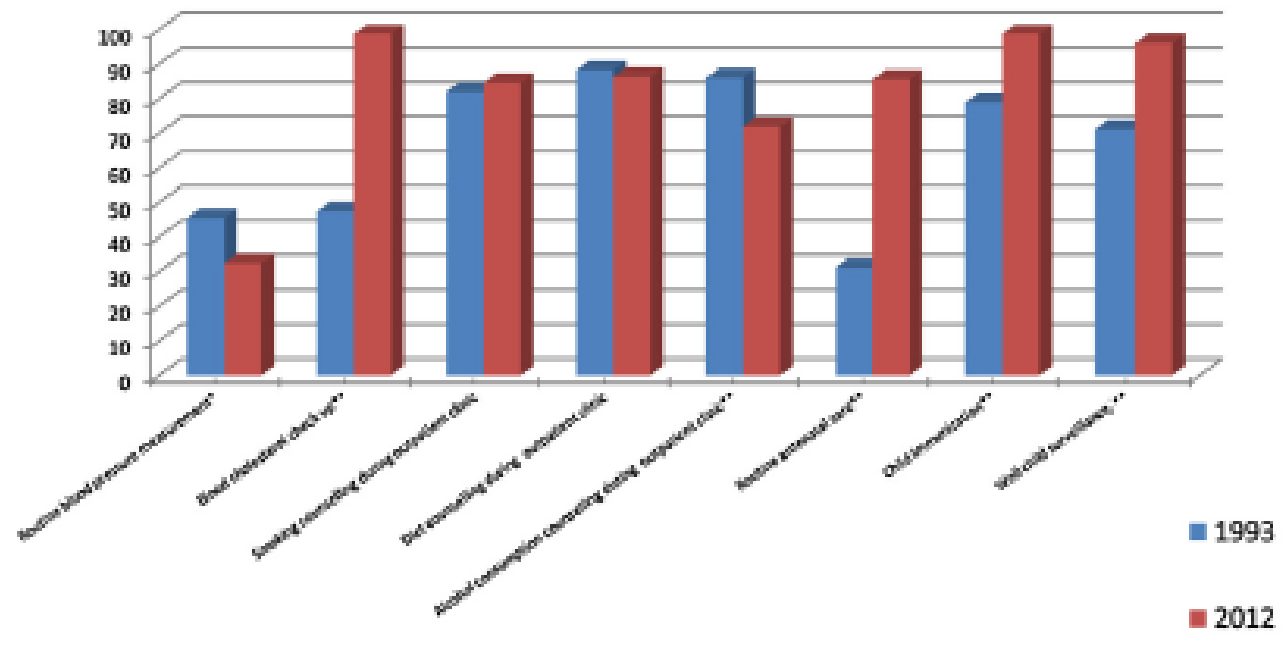

"percentoges reflect the PCDs who are involved in given preventive care service (" $\left.p=0.001,{ }^{*} p<0.001\right)$

b) Treatment of chronic diseases (\%)

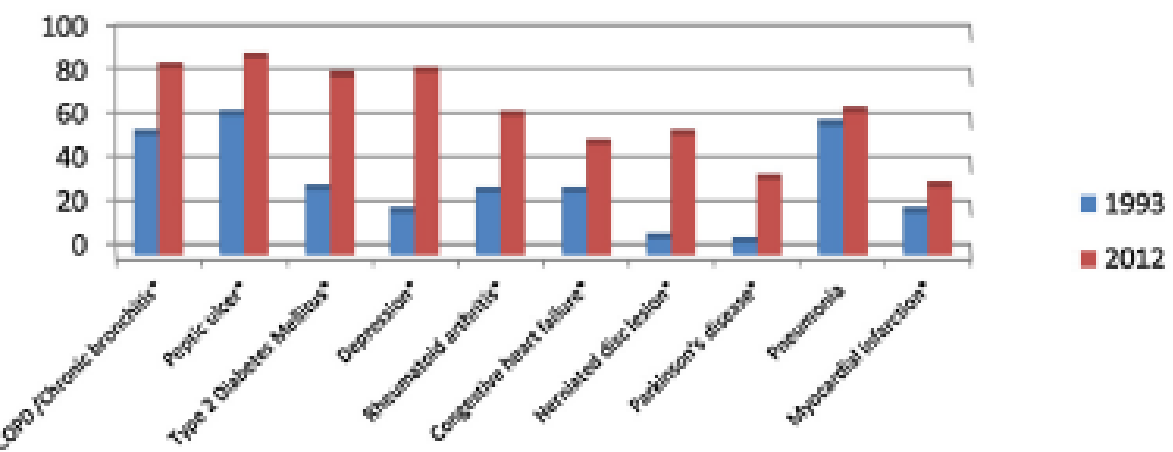

"percentages reflect the PCDs who are usually or almost always involved in given disease management $\left({ }^{*} p<0.001\right)$

\section{c) Medical and minor surgical procedures (\%)}

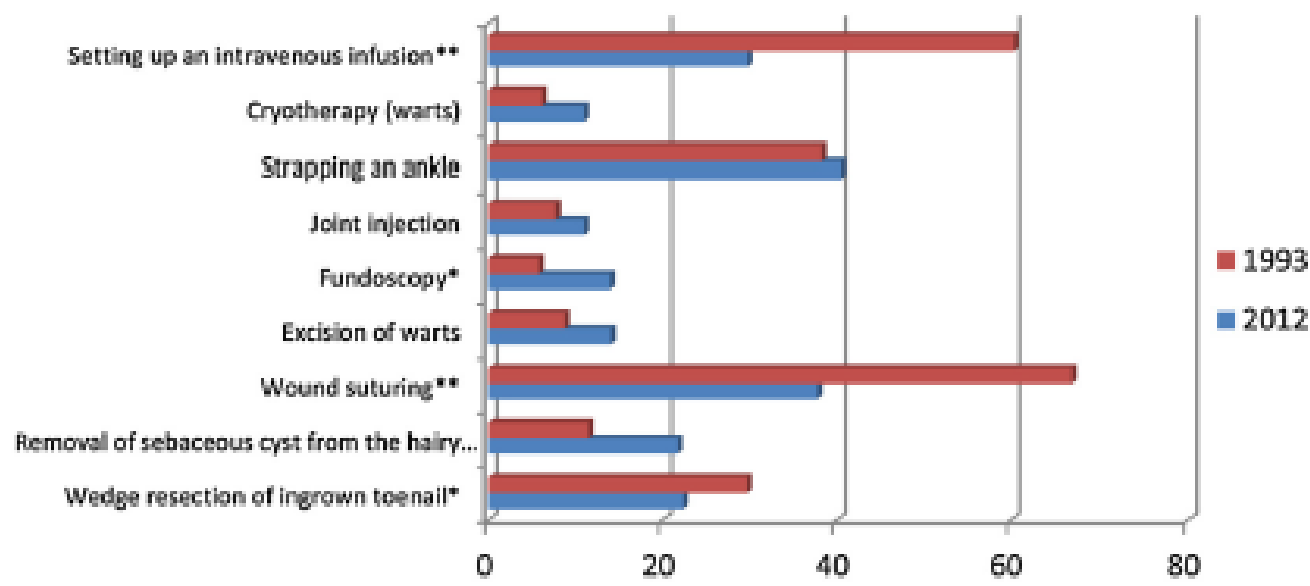

"percentages reflect the PCDs who are usually or almost always perform the given procedures $\left({ }^{*} p<0.05,{ }^{* *} p<0.001\right)$

Fig 2. Involvement of PCDs in various services in 1993 and 2012. 
Akman, M., Sakarya, S, Sargin, M., Ünlüoğlu, I., Taşkın Eğici, M., Boerma, W.G.W., Schäfer, W.L.A. Changes in primary care provision in Turkey: a comparison of 1993 and 2012. Health Policy: 2016

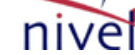

\begin{tabular}{|c|c|c|c|c|}
\hline \multirow{2}{*}{$\begin{array}{l}\text { Process level dimensions of } \\
\text { primary care }\end{array}$} & \multirow{2}{*}{ Assessment criteria } & \multirow{2}{*}{ Change between 1993-2012 } & \multicolumn{2}{|l|}{ Reported outcome } \\
\hline & & & Improvement & Decline \\
\hline \multirow[t]{2}{*}{ Coordination } & Specialist outreach & $\begin{array}{l}\text { Transformation of HCs to } \\
\text { FHCs }\end{array}$ & & $\begin{array}{l}\text { Less contact with } \\
\text { specialists }\end{array}$ \\
\hline & $\begin{array}{l}\text { Cooperation within primary } \\
\text { care }\end{array}$ & & $\begin{array}{l}\text { More contact with PCDs, } \\
\text { nurses and pharmacists }\end{array}$ & \\
\hline \multirow[t]{5}{*}{ Comprehensiveness } & Preventive care & $\begin{array}{l}\text { Incentives for preventive } \\
\text { care }\end{array}$ & $\begin{array}{l}\text { Increased involvement of } \\
\text { PCDs in antenatal and child } \\
\text { care }\end{array}$ & $\begin{array}{l}\text { Decreased preventive } \\
\text { services for non-paid } \\
\text { incentives like blood } \\
\text { pressure measurement }\end{array}$ \\
\hline & $\begin{array}{l}\text { Medical Technical } \\
\text { procedures }\end{array}$ & $\begin{array}{l}\text { Introduction of malpractice } \\
\text { insurance }\end{array}$ & & $\begin{array}{l}\text { Decrease in riskier medical } \\
\text { procedures like intravenous } \\
\text { infusion, wound suturing }\end{array}$ \\
\hline & & $\begin{array}{l}\text { Assignment of one PCD for } \\
\text { a specific population }\end{array}$ & & Lengthy patient list \\
\hline & First contact of care & $\begin{array}{l}\text { Improved status of PCD } \\
\text { including name change }\end{array}$ & $\begin{array}{l}\text { Increase in first contact of } \\
\text { care for adult patients }\end{array}$ & \\
\hline & $\begin{array}{l}\text { Involvement in chronic } \\
\text { disease }\end{array}$ & $\begin{array}{l}\text { Epidemiologic and } \\
\text { demographic transition }\end{array}$ & $\begin{array}{l}\text { Increase in involvement of } \\
\text { chronic disease treatment }\end{array}$ & \\
\hline Continuity & Medical record keeping & Computerization & $\begin{array}{l}\text { Increased medical record } \\
\text { keeping }\end{array}$ & \\
\hline Access & Home visits & Lengthy Patient list & & $\begin{array}{l}\text { Decrease in number of } \\
\text { home visits }\end{array}$ \\
\hline
\end{tabular}

